\title{
Real-Time Hardware-in-the-Loop Platform for Hybrid AC/DC Power System Studies
}

\author{
Tibin Joseph, Member, IEEE, Khadijat Jose, Member, IEEE, Carlos Ugalde Loo, Member, IEEE, \\ Gen Li, Member, IEEE, and Jun Liang, Senior Member, IEEE \\ School of Engineering, Cardiff University, CF24 3AA, Cardiff, Wales, United Kingdom. \\ Email: [JosephT, JoseK2, Ugalde-LooC, LiG9, LiangJ1]@ cardiff.ac.uk.
}

\begin{abstract}
Conventional power system studies are normally performed using offline analytical tools and computer-based simulations. Hardware-in-the-loop (HiL) configurations are very helpful to carry out experimental tests in a safe environment without affecting the operation of a practical power system. Following this line, a real-time HiL (RT-HiL) platform suitable for a wide range of power system studies is presented in this paper. Emphasis is placed on the individual components of the platform. To demonstrate the capabilities of the RT-HiL configuration, two case studies are presented: subsynchronous resonance damping and fast frequency support provision. The ac grids are modeled in the RT simulator, while dc networks are implemented in a physical test-bed. The ability of the RT-HiL platform to emulate ac/dc interactions and grid support services is shown. For completeness, experimental results are compared against PSCAD simulation results—showing a good agreement. It should be emphasized that the presented experimental platform goes beyond conventional HiL set-ups-instead representing a hybrid hardware-based emulator with RT-HiL simulation.

Index Terms-Subsynchronous resonance, fast frequency support, high-voltage direct-current, voltage source converters, real-time, hardware-in-the-loop.
\end{abstract}

\section{INTRODUCTION}

Modern power systems are expected to become cleaner whilst remaining affordable and secure, with more non-fossil fuel based generation supported by power electronic converters. In the UK, the grid integration of low-carbon renewable energy resources is expected to rise dramatically in the near future. The installation of fairly new technologies to the UK power system such as series compensation and high-voltage direct-current (HVDC) systems has been necessary to transfer the additional renewable-based generation to consumers [1]. However, this has brought operability challenges which were not present before [1]-[3]. In addition, managing new assets (e.g. power flow control devices such as flexible ac transmission devices -FACTSand HVDC systems) has become an escalated task for grid owners and operators [4]. To this end, modeling tools and software platforms have been widely investigated to assess the overall system security and stability upon such a changing grid structure [1]-[3], [5].

Stability studies considering power converter devices typically rely on offline simulation tools, where fast acting switching dynamics and complex controllers may be implemented in detail. However, critical dynamics and measurement uncertainties may not be accurately incorporated by the models and this, in turn, may hide complex interactions present in real power systems [6]-[8]. To bridge this gap, real-time (RT) simulators have been devised to provide a high fidelity simulation environment. An RT simulator can be employed to test the performance of physical scaled-down power electronic based devices through hardware-in-the-loop (HiL) experiments [7], [8]. RT-HiL is an attractive option for safe yet realistic power system studies as it combines the advantages of numerical simulation of complex system dynamics and laboratory testing of embedded systems under one platform [7]-[9]. Such a configuration can be employed to assess the suitability of simulation-based models and to validate the feasibility of innovative control schemes.

Substantial research using RT-HiL configurations for power system studies can be found in the open literature [9]-[22]. For instance, the testing and validation of control schemes and methodologies for FACTS and HVDC systems have been reported in [9]-[11]. Transient stability studies have also received significant attention. For example, [16], [17] focus on subsynchronous oscillation studies and detailed shaft models of synchronous generators, HVDC systems and series-compensated ac lines. Provision of damping using power converters to enhance power system stability has been studied in [18]. Studies focusing on multi-terminal HVDC (MTDC) systems for frequency support and power flow control have been presented in [12], [19], [20]. However, sufficient detail on the RT-HiL platform and its components is normally omitted in the papers as the scope of the work is usually not the platform itself.

To this end, this paper presents an RT-HiL platform suitable for a wide range of hybrid ac/dc power system studies. Emphasis is made on the platform and its building elements. Two quite distinct case studies are presented to demonstrate the capabilities of the RT-HiL configuration: subsynchronous resonance (SSR) damping and fast frequency support provision. To carry out the studies, a reduced order representation of the Great Britain (GB) power system is modeled in an RT digital simulator (RTDS) and an analogue voltage source converter (VSC) based HVDC test-rig is connected to the RTDS through a power amplifier. A comparison of experimental results with those obtained from PSCAD software simulations is provided for completeness.

The experimental platform presented in this work is a flexible hybrid hardware-based emulator with embedded RT-HiL simulation that can be used for: 1) small and 


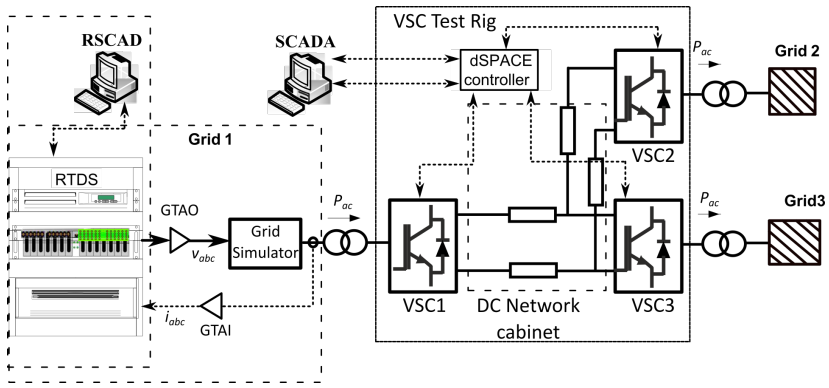

Figure 1. High-level schematic diagram of the RT-HiL configuration.

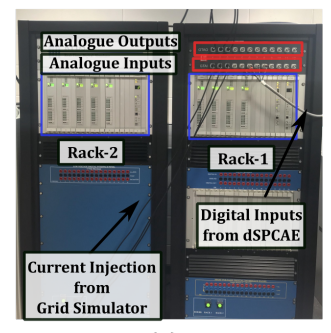

(a)

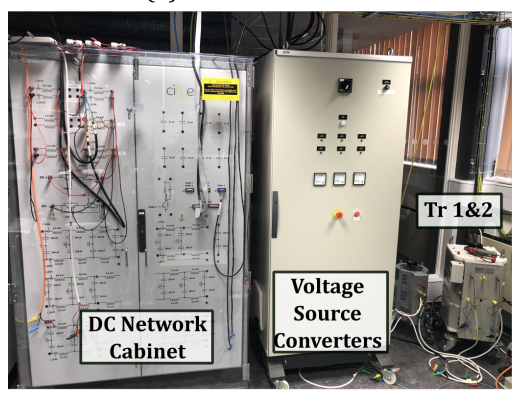

(c)

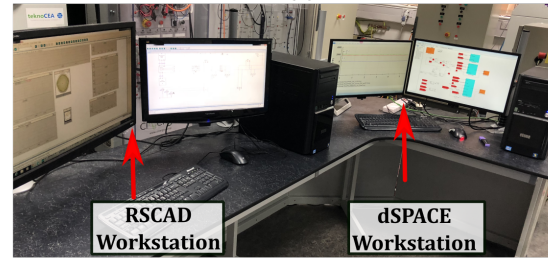

(d)

Figure 2. Physical setup: (a) RTDS; (b) GSs; (c) VSC test-rig; (d) control desks.

large disturbance studies; 2) testing and validating ancillary services provision; 3) grid synchronisation, power quality assessment, and power system protection. Although this is a scaled-down platform, its ratings are sufficient to represent the dynamics of a real power system, in a safe environment, and to test innovative devices and control systems ahead of commissioning. It is also scalable and it can be employed to emulate dangerous operating conditions such as SSR occurrence-without the risk of power system failure and danger to personnel.

\section{Multi-Platform RT-Hil Configuration}

A high-level schematic diagram of the RT-HiL configuration is shown in Fig. 1. To understand its operation better, the individual units are first described. The individual physical components are depicted in Fig. 2. The setup consists of three VSCs, one dSPACE control card, one dc network cabinet, three grid simulators (GSs) and two RTDS cubicles.
Table I

SPECIFICATIONS AND PARAMETERS OF THE RT-HIL SYSTEM AND FOR SIMULATION STUDIES

\begin{tabular}{llll}
\hline Devices & Specifications & Simulation & Experiment \\
\hline \multirow{4}{*}{ Converters } & Grid 1 power & $1000 \mathrm{MW}$ & $1500 \mathrm{~W}$ \\
& AC voltage & $400 \mathrm{kV}$ & $140 \mathrm{~V}$ \\
& DC voltage & $640 \mathrm{kV}$ & $250 \mathrm{~V}$ \\
& AC inductors & $11.35 \mathrm{mH}$ & $2.2 \mathrm{mH}$ \\
\hline \multirow{2}{*}{ DC lines } & $L_{13}$ & $43.12 \mathrm{mH}$ & $11.8 \mathrm{mH}$ \\
& $L_{23}$ & $11.01 \mathrm{mH}$ & $2.4 \mathrm{mH}$ \\
& $R_{13}$ & $1.075 \Omega$ & $0.98 \Omega$ \\
& $R_{23}$ & $0.204 \Omega$ & $0.26 \Omega$ \\
\hline \multirow{2}{*}{ DC capacitors } & $C_{g 1}, C_{g 2}, C_{g 3}$ & $1050 \mu \mathrm{F}$ & $1020 \mu \mathrm{F}$ \\
\hline Simulator & $\mathrm{dSPACE}$ DS 1005 / ControlDesk $3.2(\mathrm{SIMULINK})$ \\
\hline
\end{tabular}

A. VSC-HVDC Test-Rig

This consists of three two-level VSCs with a rated capacity of $2 \mathrm{~kW}$ each, an embedded computer (dSPACE), three transformers, and ac and dc inductors. The rated voltage of the VSCs is $140 \mathrm{~V}$ rms (line-to-line) ac and $250 \mathrm{~V}$ dc. VSC1 and VSC3 are powered by the main grid via two $400 / 140 \mathrm{~V}$ auto-transformers. VSC2 is powered via an isolation transformer and connected to a GS, which controls its voltage to $140 \mathrm{~V}$ (line-to-line). The dSPACE DS 1005 PPC board performs data acquisition, monitoring and control of each VSC. Digital and analogue signals are transmitted back and forth between the dSPACE and the RTDS through the interface board as shown in Fig. 2(c). The control desk uses a Simulink interface. The specifications and parameters of the VSC-HVDC test-rig are provided in Table I.

\section{B. DC Network Cabinet}

This is shown in Fig. 2(c). It contains the necessary components to form a dc network, including a scaled-down representation of dc cable circuits, a dc short circuit generator and an insulated-gate bipolar transistor (IGBT) controlled variable resistor. Different network topologies (dc link, radial or meshed MTDC grids) can be achieved through suitable connection of the dc cables by using additional resistors and dc inductors. The specifications and parameters of the de network cabinet are provided in Table I.

\section{AC Grid Simulators}

The GSs, shown in Fig. 2(b), serve as an interface between the RTDS and the VSC test-rig. GS1 is a four-quadrant power amplifier rated at $2 \mathrm{kVA}$ and $270 \mathrm{~V}$ rms (line-to-ground). The amplifier absorbs power from VSC2 and injects it back to the mains supply. The GS receives a low voltage signal from the analogue output cards (GTAO) of the RTDS. With this, it produces a three-phase mains supply voltage of $140 \mathrm{~V}$. This supply voltage is the input of the isolation transformer connected to VSC2 of the HVDC test-rig. Therefore, $140 \mathrm{~V}$ in the test-rig is equivalent to $400 \mathrm{kV}$ in the RTDS. This is the forward path between the RTDS and VSC test-rig. Finally, a three-phase current measurement from the test-rig is fed back 
to the RTDS via its analogue input cards (GTAI). This closes the loop between the RTDS and the VSC test-rig.

\section{Real-Time Digital Simulator}

The RTDS, shown in Fig. 2(a), is used for performing simulations in real time. The RSCAD software of the RTDS can be used to build complex power system models. The node voltage measurement in a prospective system is scaled-down and transformed to an analogue output signal via the GTAO cards of the RTDS. This analogue output signal is exported to the GS. The RTDS also receives analogue current measurements from the GS through the GTAI cards of the RTDS. This current measurement is scaled-up and is represented in the simulator as a current source connected to the same node.

\section{E. Signal Transition and Scaling in RT-HiL}

Fig. 3(a) shows the transformation process from the RTDS node voltage to the test-rig voltage. With the aid of a GS, the high voltage $(400 \mathrm{kV})$ of the RTDS is scaled down and seen as a $140 \mathrm{~V}$ ac voltage at the VSC test-rig; i.e. a $400 \mathrm{kV} / 140$ $\mathrm{V}$ transformation is achieved. Also, as shown in Fig. 3(b), the current from the VSC is scaled-up and transmitted to the RTDS through the GTAI. A phase compensator is also implemented to remove the transmission delay of the VSC2 current.

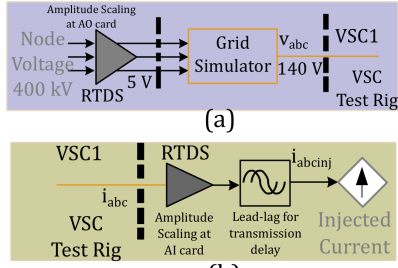

(b)

Figure 3. RT-HiL Configuration: (a) voltage transition from the RTDS to the VSC test-rig; (b) current transition from the VSC test-rig to the RTDS.

\section{Power System Studies USING The RT-HiL PLATFORM}

To demonstrate the capabilities of the RT-HiL test-bench shown in Fig. 1, two case studies have been performed. These consist of HiL experiments involving the model of a simplified power system and the physical connection with the VSC-HVDC test-rig.

\section{A. System Configuration: GB Transmission Network}

The three-machine reduced model of the GB transmission system is adopted in this paper as a test system to demonstrate the RT-HiL platform. The model is a simplified representation of GB network dividing the mainland grid into three major generation areas: Southern Scotland (SS), Northern Scotland (NS) and England and Wales (E\&W), with respective ratings of 2800, 2400 and 21000 MVA. This has been implemented on the RTDS. Although the adopted system configuration is arguably a rather simplified version of a real power system, it provides sufficient information to study, understand and test power system stability phenomena. For additional information on the test system, the reader is referred to [17], [18], [23].

\section{B. Case 1: Analysis and Damping of SSR}

National Grid (the GB system operator) has considered grid reinforcements in the form of series compensation to facilitate the transmission of additional wind power from Scotland to major load centres in the South without the need for construction of new onshore overhead transmission lines. However, the inclusion of series compensation can bring the risk of SSR - an instability condition with potentially disastrous consequences resulting from the interaction of electrical modes of series-compensated lines and nearby mechanical modes of turbo-generator shafts [23].

To facilitate SSR studies, the transmission line connecting the NS generator has been upgraded with series compensation, as shown in Fig. 4(a) [17], [23], [24]. The NS generator has been modeled in detail as a multi-mass system that includes four turbine sections, an exciter, and the generator itself. The remaining two machines ( $\mathrm{SS}$ and $\mathrm{E} \& \mathrm{~W}$ ) were modeled as single mass turbo-generators [23]. The VSC-HVDC link is connected between Buses 1 and 2 (see Fig. 4(a)). The RT-HiL implementation of the GB system to perform SSR studies is shown in Fig. 4(b).

Experiments were designed to assess the effect of a change in series compensation percentage (i.e. a small disturbance) on the RT operation of the system, with results shown in Fig. 5. The experiment starts with the system in steady-state at $30 \%$ series compensation. This condition does not produce SSR. At $t=4 \mathrm{~s}$ the value of series compensation is modified to $40 \%$. After such a disturbance, the system develops SSR and becomes unstable, evidenced by the growing oscillations in the system measured variables. Without proper countermeasures in place, the HVDC link operation could also be compromised.

The control flexibility of the VSC link can be exploited to provide SSR damping. To serve this purpose, an SSR damper (SSRD) is designed and embedded in the VSC station as an auxiliary controller to eliminate SSR upon occurrence. This is shown in Fig. 6. The SSRD consists of a 2 nd order band-pass filter. Its transfer function is expressed as:

$$
B_{t m}(s)=k_{M M D} \cdot \frac{\frac{s}{\omega_{c n}}}{1+2 \xi \frac{s}{\left(\omega_{c n}\right)^{2}}+\left(\frac{s}{\omega_{c n}}\right)^{2}}
$$

where $\omega_{c n}$ is the center frequency of the filter, $\xi$ the damping factor and $k_{M M D}$ denotes the filter gain.

Experimental tests were repeated with the SSRD in place, with results shown also in Fig. 5. It can be noticed that oscillations in the frequency of the transmission line and shaft torques converge to steady-state following a transient period once the SSRD is in operation.

For completeness, the experimental results are compared against simulation results obtained from PSCAD/EMTDC. These are shown in Fig. 7. As it can be observed, experimental and simulation results show a good agreement and evidence a successful performance of the SSR damping scheme.

\section{Case 2: Frequency Support from MTDC Grids}

For this case study, the GB system model presented in the previous section is also employed. Fig. 8 shows a schematic of 


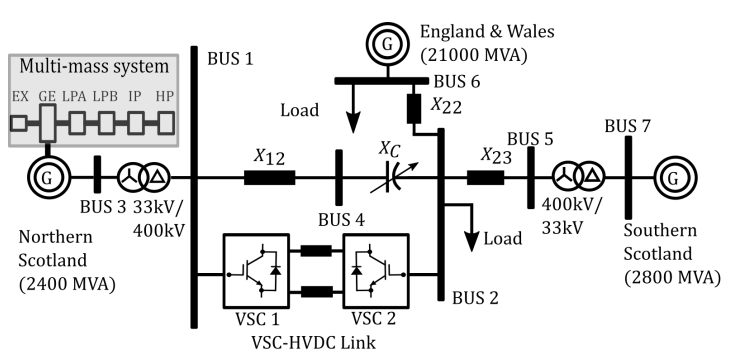

(a)

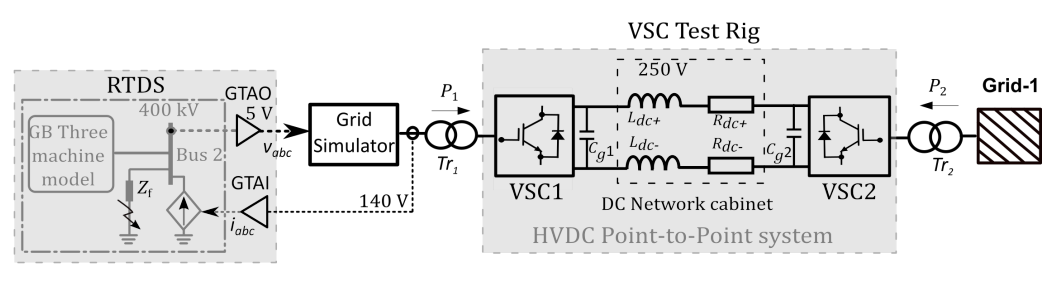

(b)

Figure 4. Test system for Case 1. (a) Three-machine GB system configuration; (b) RT-HiL implementation.

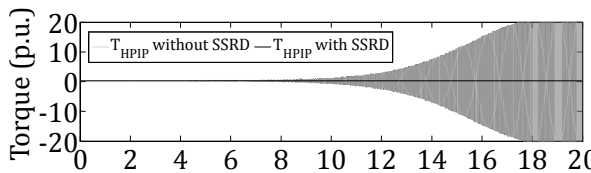

(a)

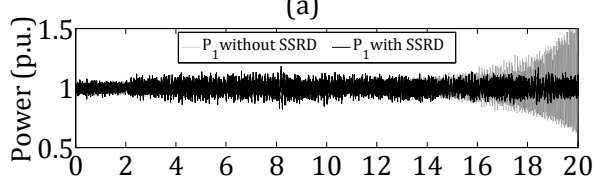

(b)

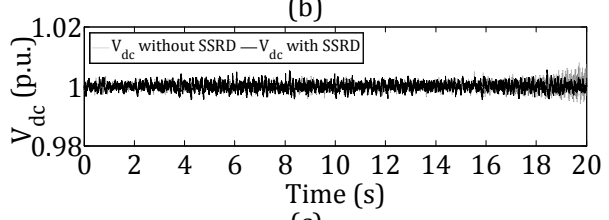

(c)

Figure 5. Experimental results upon a small disturbance (change in series compensation level): (a) selected torque interaction in the multi-mass shaft of the NS generator (high to intermediate pressure turbines); (b) output power at $\mathrm{VSC} 1$; (c) dc link voltage.

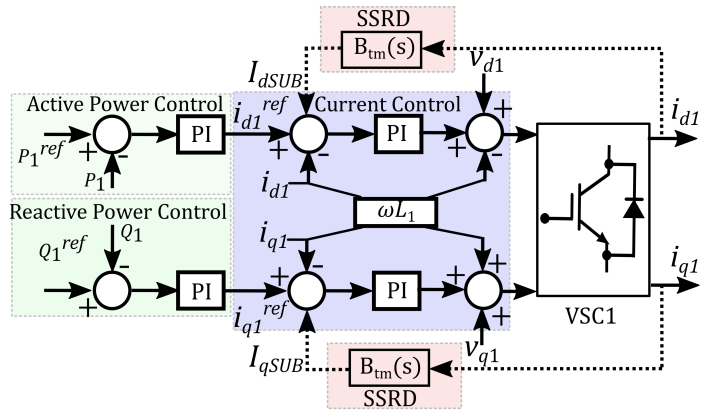

Figure 6. VSC control structure with embedded auxiliary SSRD

the test system configuration. The three-machine GB system is also modeled in the RTDS using RSCAD, as shown in Fig. 8(a). The experiment considers a fast frequency support coordination between different onshore ac grids interconnected by an MTDC grid following a frequency event. An alternative coordinated control (ACC) support scheme is adopted [20], [25]. The meshed MTDC grid is afforded by using the three-terminal VSC-HVDC test-rig, which is controlled via the dSPACE computer. The dSPACE and RTDS models are interconnected by GS1, forming the HiL setup (see Fig. 8(b)). Relevant specifications and parameters for Case 2 are included in Table I. The control modes of the converters are shown in Table III.

As shown in Fig. 9, the ACC scheme uses a $V_{d c}-P$ droop during normal operation and switches to a $f-P$ droop during
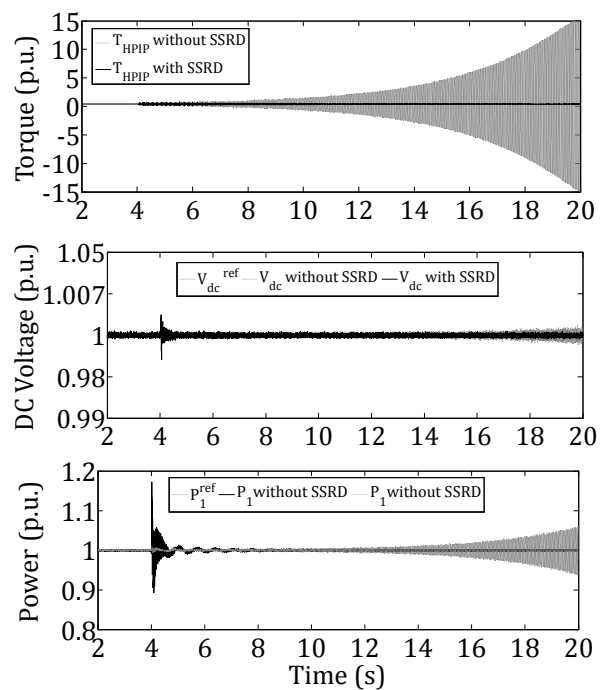

(a) Simulation
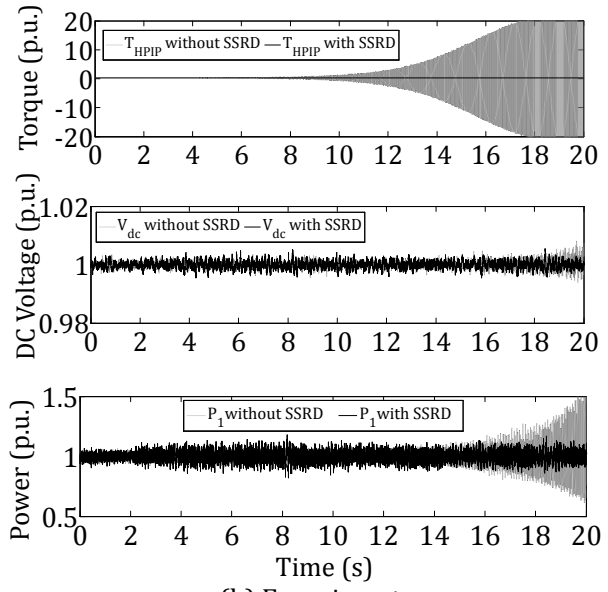

(b) Experiment

Figure 7. Comparison of simulation and experimental results for Case 1

a disturbance [25]. This can be expressed as:

$$
\begin{aligned}
& P_{d c}^{*}=P_{d c, 0}-k_{v p}\left(V_{d c, 0}-V_{d c}\right), \text { if }\left(f_{o n, 0}-f_{o n}\right)<\Delta f_{d b} \\
& P_{d c}^{*}=P_{d c, 0}+k_{f p}\left(f_{o n, 0}-f_{o n}\right), \text { if }\left(f_{o n, 0}-f_{o n}\right)>\Delta f_{d b}
\end{aligned}
$$

where $k_{v p}$ is the dc voltage-active power droop gain and $k_{f p}$ is the frequency-power droop gain. After the disturbance event is over, the system returns to the original $V_{d c}-P$ droop when $\left(f_{o n, 0}-f_{o n}\right)<\Delta f_{d b}$. A sample-and-hold block is used during the switching process to hold the active power pre-disturbance value. 

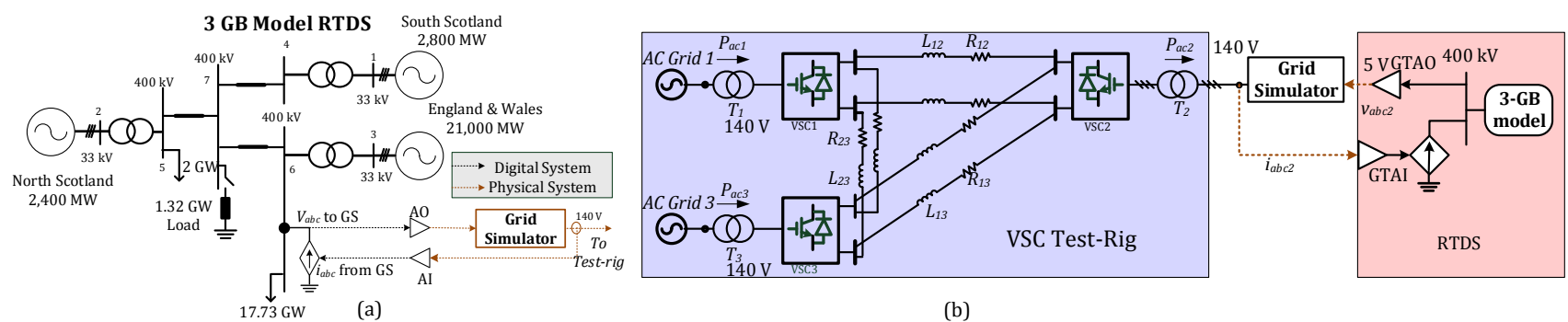

(b)

Figure 8. Test system for Case 2. (a) Three-machine GB system configuration; (b) RT-HiL implementation.

Table II

TEST-Rig SPECIFICATIONS AND PARAMETERS FOR CASE 1

\begin{tabular}{lll}
\hline Devices & Specifications & Rating \\
\hline & Rated power & $1 \mathrm{~kW}(1 \mathrm{p} . u)$. \\
Converters & $\begin{array}{l}\text { Rated ac voltage } \\
\text { Rated dc voltage } \\
\text { Topology }\end{array}$ & $\begin{array}{l}140 \mathrm{~V} \\
250 \mathrm{~V}(1 \mathrm{p} . u .) \\
\text { Two-level }\end{array}$ \\
\hline AC inductors & $L_{g 1}, L_{g 2}$ & $2.2 \mathrm{mH}$ \\
\hline DC lines & $L_{d c}, R_{d c}$ & $2.4 \mathrm{mH}, 0.26 \Omega$ \\
\hline DC capacitors & $C_{g 1}, C_{g 2}$ & $1020 \mu \mathrm{F}$ \\
\hline SSRD gain & $k_{M M D}$ & 1 \\
\hline Control system & dSPACE DS1005/ControlDesk 3.2 (Simulink) \\
\hline RTDS & Racks: 2. Cards: 2 GTWIF, 4 PB5 \\
& (2 GTDI, 2 GTDO, 2 GTAI, 2 GTAO, 2 GTNET) \\
\hline
\end{tabular}

Table III

CONTROL MODE OF VSCS FOR CASE 2.

\begin{tabular}{cccc}
\hline \hline $\begin{array}{c}\text { Converter } \\
\text { Modes }\end{array}$ & $\begin{array}{c}\text { Start-up } \\
\text { Control }\end{array}$ & $\begin{array}{c}\text { Steady-state } \\
\text { Control }\end{array}$ & $\begin{array}{c}\text { ACC } \\
\text { Control }\end{array}$ \\
\hline VSC1 & Constant $V_{d c}-Q$ & $P-V_{d c}$ droop & $f-V_{d c}$ droop \\
\hline VSC2 & Constant $P-Q$ & $V_{d c}-P$ droop & $f-P$ droop \\
\hline VSC3 & Constant $P-Q$ & $V_{d c}-P$ droop & $f-P$ droop \\
\hline
\end{tabular}

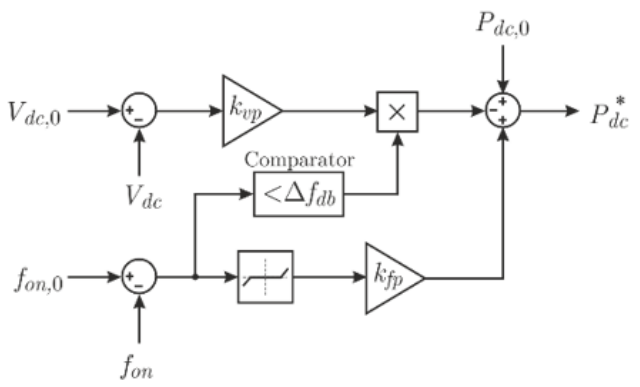

Figure 9. Alternative coordinated control scheme.

A frequency event resulting from a loss of $1320 \mathrm{MW}$ of generation is simulated in the three-machine model (see Fig. 8(a)). Fig. 10 shows experimental results when the ACC scheme is fitted only in VSC2. In response to the supplementary $f-P$ droop, VSCs 1 and 3 provide extra power to VSC2. There is a frequency deviation of about $0.43 \mathrm{~Hz}$, and about 0.5 p.u. extra power is delivered to VSC2. The frequency of the other two grids drops to $49.91 \mathrm{~Hz}$.

For completeness, a comparison between the experimental results with those obtained with PSCAD simulations is made (see Fig. 11). However, as the two systems have different bases, results are obtained in per unit (base values are provided in Table I). In this case, the ACC scheme has been fitted to all converters. As it can be observed, a dc voltage deviation occurs due to the operation of the $f-P$ droops. This characteristic is a result from VSC2 and VSC3 entering their frequency sensitive modes around $t=3.5 \mathrm{~s}$-as seen in the yellow and blue trace of Fig. 11(c). In the simulation, this causes VSC1 to reduce its power export to VSC2, and VSC3 increases its output to compensate for the power reduction from VSC1. This behavior is also present in the experimental results.

The power being supplied to VSC2 in both experimental and simulation results shows a good agreement. A power increase of about 0.65 p.u. flows from VSC2 to the ac grid in both cases, as shown in Fig. 11(b). Also, the frequency deviation in ac grid 2 coincides in both sets of results, with a $\Delta f_{2}$ of $0.43 \mathrm{~Hz}$. As it can be observed, sudden undesirable changes in power and dc voltage are exhibited when the supplementary frequency controller is fitted in all converters-even when frequency support is achieved.

\section{CONClusion}

An RT-HiL experimental platform has been presented in this paper. The platform considers an RTDS connected to a VSC-HVDC test-rig through a power amplifier. A dc network is available, enabling the possibility to perform studies involving dc grids. The capabilities of the developed configuration to perform power system studies were demonstrated through two quite distinct examples. These include the analysis and damping of SSR using an auxiliary control loop of a VSC terminal and the provision of fast frequency support from MTDC grids following a frequency event. The results obtained from the experimental platform show a good agreement with those obtained from computer simulations performed in PSCAD/EMTDC - providing credibility to both the simulation models and the hardware configuration.

The case studies presented in this paper show the flexibility of the RT-HiL configuration, as both small and large disturbances have been considered and provision of ancillary services has been assessed. Given its scalability, it is possible to increase the processing capabilities by including additional RTDS cards and to widen the scope of system studies 


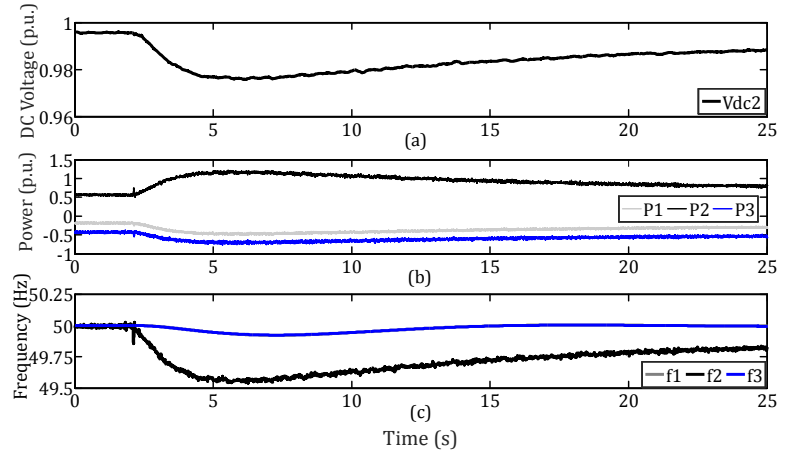

Figure 10. Experimental results. System response after loss of $1320 \mathrm{MW}$ (ACC fitted in VSC2 only): (a) dc voltage (p.u.); (b) power of VSCs 1, 2 and 3 (p.u.); (c) frequency of Grids 1, 2 and 3.
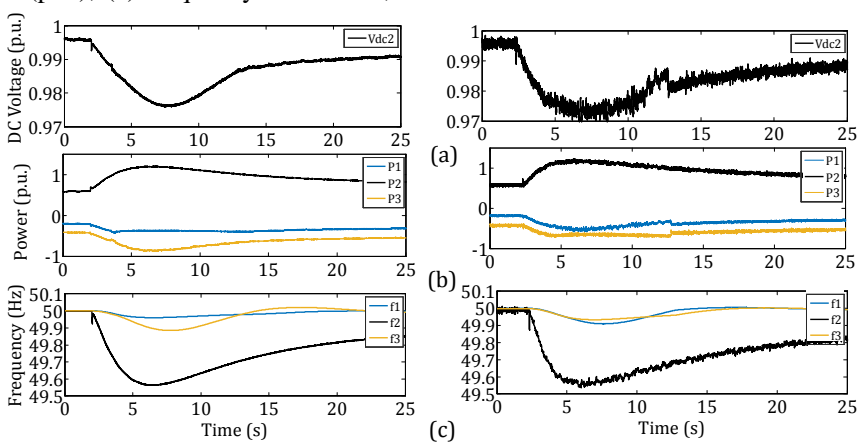

Figure 11. PSCAD results (left-hand side) and experimental results (right-hand side) of system response due to $1320 \mathrm{MW}$ generation loss, with ACC fitted in all converters: (a) dc voltage (p.u.); (b) power of VSCs 1, 2 and 3 (p.u.); (c) frequency of Grids 1, 2 and 3.

by including additional hardware; e.g. incorporating wind and solar emulators and energy storage. Future work could consider expanding on aspects related to dc grid control and their implementation and verification in the RT-HiL platform.

\section{ACKNOWLEDGMENT}

The authors gratefully acknowledge the financial support from RCUK-EPSRC and National Grid under the project EP/L021455/1 and by the EU FP7 Programme through the project BEST PATHS, grant agreement number 612748. The authors also gratefully acknowledge Dr. Oluwole D. Adeuyi and Dr. Senthooran Balasubramaniam for their contributions on developing the RT-HiL platform.

\section{REFERENCES}

[1] IET GB Power System Modelling Capability Reports, IET Report for the Council of Science and Technology, Aug 2017.

[2] C. S. Edrington, M. Steurer, J. Langston, T. El-Mezyani and K. Schoder, "Role of Power Hardware in the Loop in Modeling and Simulation for Experimentation in Power and Energy Systems," Proceedings of the IEEE, vol. 103, no. 12, pp. 2401-2409, Dec. 2015

[3] C. Rehtanz and X. Guillaud, "Real-time and co-simulations for the development of power system monitoring, control and protection," Power Systems Computation Conf. (PSCC), Genoa, Italy, pp. 1-20, 2016.

[4] T. Joseph, C. E. Ugalde-Loo, J. Liang and P. F. Coventry, "Asset Management Strategies for Power Electronic Converters in Transmission Networks: Application to HVdc and FACTS Devices," IEEE Access, vol. 6, pp. 21084-21102, 2018.

[5] C. E. Ugalde-Loo, et. al., "Open access simulation toolbox for the grid connection of offshore wind farms using multi-terminal HVDC networks," 13th IET Intl. Conf. on AC DC Power Trans. (ACDC2017), Manchester, UK, pp. 1-6, 2017.
[6] G. F. Lauss, M. O. Faruque, K. Schoder, C. Dufour, A. Viehweider and J. Langston, "Characteristics and design of power hardware-in-the-loop simulations for electrical power systems," IEEE Trans. Ind. Electron., vol. 63, no. 1, pp. 406-417, 2016.

[7] M. O. Faruque, et. al., "Real-time Simulation Technologies for Power Systems Design, Testing, and Analysis," IEEE Power Energy Technol. Syst. J., vol. 2, no. 2, pp. 63-73, 2015.

[8] X. Guillaud, et. al., "Applications of Real-Time Simulation Technologies in Power and Energy Systems," IEEE Power Energy Technol. Syst. J., vol. 2, no. 3, pp. 103-115, 2015.

[9] A. S. Vijay, S. Doolla and M. C. Chandorkar, "Real-Time Testing Approaches for Microgrids," IEEE J. Emerg. Sel. Topics Power Electron., vol. 5, no. 3, pp. 1356-1376, Sept. 2017.

[10] A. S. Musleh, S. M. Muyeen, A. Al-Durra and I. Kamwa, "Testing and validation of wide-area control of STATCOM using real-time digital simulator with hybrid HIL-SIL configuration," IET Gen. Trans. \& Distr. vol. 11, no. 12, pp. 3039-3049, 2017.

[11] P. Mitra and G. K. Venayagamoorthy, "Wide area control for improving stability of a power system with plug-in electric vehicles," IET Gen. Trans. \& Distr., vol. 4, no. 10, pp. 1151-1163, Oct. 2010.

[12] S. Balasubramaniam, C. E. Ugalde-Loo, J. Liang, T. Joseph, R. King and A. Adamczyk, "Experimental Validation of Dual H-Bridge Current Flow Controllers for Meshed HVdc Grids," IEEE Trans. Power Del., vol. 33, no. 1, pp. 381-392, Feb. 2018.

[13] S. Dennetiere, H. Saad, B. Clerc, E. Ghahremani, W. Li and J. Belanger, "Validation of a MMC model in a real-time simulation platform for industrial HIL tests," 2015 IEEE Power \& Energy Society General Meeting, Denver, pp.1-5, 2015.

[14] P. C. Kotsampopoulos, F. Lehfuss, G. F. Lauss, B. Bletterie and N. D. Hatziargyriou, "The Limitations of Digital Simulation and the Advantages of PHIL Testing in Studying Distributed Generation Provision of Ancillary Services," IEEE Trans. Ind. Electron., vol. 62, no. 9, pp. 5502-5515, Sept. 2015.

[15] B. Lundstrom, B. Palmintier, D. Rowe, J. Ward and T. Moore, "Trans-oceanic remote power hardware-in-the-loop: multi-site hardware, integrated controller, and electric network co-simulation," IET Gen. Trans. \& Distr., vol. 11, no. 18, pp. 4688-4701, 2017.

[16] J. Zhang, X. Xiao, P. Zhang, C. Luo, Y. Wu, J. Lu and L. Ren, "Suppressing intermittent subsynchronous oscillation via subsynchronous modulation of reactive current," IEEE Trans. Power Del., vol. 30, no. 5, pp. 2321-30, 2015.

[17] T. Joseph, C. E. Ugalde-Loo, S. Balasubramaniam and J. Liang, "Real-Time Estimation and Damping of SSR in a VSC-HVDC Connected Series-Compensated System," IEEE Trans. Power Syst., vol. 33, no. 6, pp. 7052-7063, Nov. 2018.

[18] T. Joseph, "Operation and Control of Voltage Source Converters in Transmission Networks for AC System Stability Enhancement," PhD thesis, Cardiff University, 2017.

[19] K. Almaksour, S. Akkari, M. Moez Belhaouane, F. Colas and X. Guillaud, "Power-Hardware-in-the-Loop Simulation of VSC-HVDC Based Three-Terminal DC Mock-Up," 2018 Power Systems Computation Conference (PSCC), Dublin, Ireland, pp. 1-7, 2018.

[20] O. D. Adeuyi, M. Cheah-Mane, J. Liang and N. Jenkins, "Fast Frequency Response From Offshore Multiterminal VSC-HVDC Schemes," IEEE Trans. Power Del., vol. 32, no. 6, pp. 2442-2452, Dec. 2017.

[21] C. E. Ugalde-Loo, et. al., "Lessons Learnt from the BEST PATHS Project for the Integration of Offshore Wind Power Plants using Multi-Terminal HVDC Grids," CIGRE Session 2018, Paris, France, pp. $1-9,2018$.

[22] T. Joseph, C. E. Ugalde-Loo, S. Balasubramaniam and J. Liang, "Experimental Validation of an Active Wideband SSR Damping Scheme for Series-Compensated Networks," IEEE Trans. Power Del., 2019 (to appear).

[23] C. E. Ugalde-Loo, J. B. Ekanayake and N. Jenkins, "Subsynchronous resonance in a series-compensated Great Britain transmission network," IET Gen. Trans. \& Distr., vol. 7, no. 3, pp. 209-17, 2013.

[24] T. Joseph, C. E. Ugalde-Loo and J. Liang, "Subsynchronous oscillatory stability analysis of an ac/dc transmission system," 2015 IEEE Eindhoven PowerTech, Eindhoven, Netherlands, pp. 1-6, 2015.

[25] K. Jose, T. Joseph, J. Liang and C. E. Ugalde-Loo, "Auxiliary dead-band controller for the coordination of fast frequency support from multi-terminal HVDC grids and offshore wind farms," IET Ren. Pow. Gen., vol. 12, no. 13, pp. 1444-1452, 2018. 